\title{
Industrial-scale biological treatment of Chinese nutgall processing wastewater by combined expanded granular sludge bed and bio-contact oxidation
}

\author{
Yundong Wu, Kanggen Zhou ${ }^{\dagger}$, Shuyu Dong, Wei Yu, Chunsheng Liang \\ School of Metallurgy and Environment, Central South University, Changsha 410083, China
}

\section{ABSTRACT}

The industrial-scale biological treatment of Chinese nutgall processing wastewater was conducted with a $200 \mathrm{~m}^{3}$ expanded granular sludge bed reactor and a $900 \mathrm{~m}^{3}$ bio-contact oxidation reactor. The temperature of the two reactors was controlled under mesophilic conditions $\left(32-40^{\circ} \mathrm{C}\right)$, through changing the proportion of the dilution water, which was composed of steam condensation water and residual circulating water. The effluent COD, gallic acid, chroma, total nitrogen, total phosphorus levels and $\mathrm{pH}$ of both the expanded granular sludge bed and bio-contact oxidation reactors were monitored. In addition, the redox potential in the expanded granular sludge bed was recorded. The total COD removal efficiency was $87.257 \%$ when the influent COD concentration was $14251 \pm 3148 \mathrm{mg} / \mathrm{L}$, and the ratio of wastewater: dilution water was $1: 5$. The removal efficiencies of gallic acid, chroma, total nitrogen, and total phosphorus were $72.221 \%, 43.940 \%, 64.151 \%$ and $39.316 \%$, respectively. The effluent $\mathrm{pH}$ increased in either the expanded granular sludge bed reactor or the bio-contact oxidation reactor during the operation. The redox potential in the expanded granular sludge bed varied between $-367 \mathrm{mV}$ and $-435 \mathrm{mV}$. The results indicate that the combined process was suitable for treating Chinese nutgall processing wastewater.

Keywords: Bio-contact oxidation, Chinese nutgall processing wastewater, Expanded granular sludge bed, Gallic acid, Nutrient removal

\section{Introduction}

Currently, the treatment of Chinese nutgall processing wastewater is a challenge. The major products of the Chinese nutgall processing industry are gallic acid (Fig. 1(a)) [1], 3, 4, 5-trimethoxybenzoic acid (Fig. 1(b)) [2] and methyl 3, 4, 5-trimethoxybenzoate. Because the gallic acid of high quality are all produced from the alkali hydrolysis process, manufacturers generally choose the alkali hydrolysis process to produce gallic acid [3]. Most organic pollutants contained in the gallic acid wastewater are gallic acid and glucose. Our laboratory had studied the separation of gallic acid from Chinese nutgall processing wastewater by the extraction process; the gallic acid levels remaining in the raffinate measured less than $800 \mathrm{mg} / \mathrm{L} \mathrm{[4]}$, and the raffinate was collected in the regulation pool after extraction. The raw materials for producing 3, 4, 5-trimethoxybenzoic acid and methyl 3, 4, 5-trimethoxybenzoate were Chinese nutgall and dimethyl sulfate, because methyl 3, 4, 5-trimethoxybenzoate is insoluble in water, and the pollutants contained in the wastewater for producing 3, 4, 5-trimethoxybenzoic acid

This is an Open Access article distributed under the terms of the Creative Commons Attribution Non-Commercial License (http://creativecommons. org/ licenses/by-nc/3.0/) which permits unrestricted non-commercial use, distribution, and reproduction in any medium, provided the original work is properly cited.

Copyright (C) 2015 Korean Society of Environmental Engineers and methyl 3, 4, 5-trimethoxybenzoate were 3, 4, 5-trimethoxybenzoic acid, glucose, sulfate and a small amount of methanol. After the 3, 4, 5-trimethoxybenzoic acid was recovered by extraction, the 3, 4, 5-trimethoxybenzoic acid level in the raffinate was less than $20 \mathrm{mg} / \mathrm{L}$. Thus, the 3, 4, 5-trimethoxybenzoic acid content was not discussed in this study. The 3, 4, 5-trimethoxybenzoic acid and methyl 3, 4, 5-trimethoxybenzoate wastewater contained a high sulfate concentration, which would inhibit the activity of the methanogenic bacteria and liberate highly toxic hydrogen sulfide in the anaerobic biological process [5]. The 3 , 4, 5-trimethoxybenzoic acid and methyl 3, 4, 5-trimethoxybenzoate wastewater were mixed with the gallic acid wastewater raffinate in the regulation pool after being pre-treated by electrodialysis to remove the sulfate.

As environmental regulations have become increasingly stringent, the Chinese nutgall processing industry faces a severe test. Previous studies have focused on the removal of gallic acid and 3, 4, 5-trimethoxybenzoic acid from wastewater [6], but only the removal of gallic acid and 3, 4, 5-trimethoxybenzoic acid was insufficient due to the complex composition of Chinese nutgall

Received March 19, 2015 Accepted September 3, 2015

${ }^{\dagger}$ Corresponding author

Email: zhoukg63@163.com

Tel: +86-0731-88836804 Fax: +86-0731-88710171 

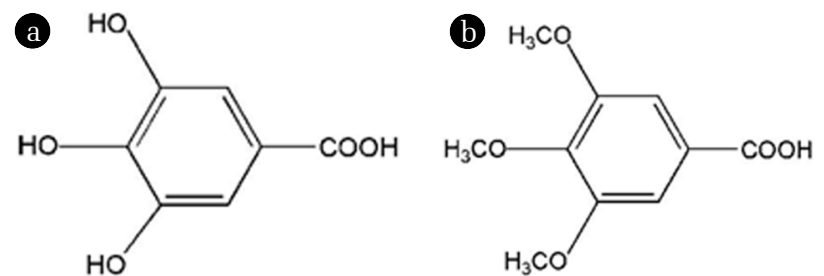

Fig. 1. Molecular structure of (a) gallic acid and (b) 3, 4, 5-trimethoxybenzoic acid.

processing wastewater. Tannic acid is the main ingredient in the Chinese nutgall, the decomposition of which would generate ten molecules of gallic acid and one molecule of glucose in the ideal case [7]. Few studies have been conducted on biological nutrient removal for Chinese nutgall processing wastewater. Most of the chemical oxygen demand (COD) remaining in the wastewater was glucose, as gallic acid and 3, 4, 5-trimethoxybenzoic acid were isolated. Glucose provides a good carbon source for the growth and metabolism of microorganisms [8, 9]. As the C:N:P ratio in the mixed wastewater was 188:3:1, which closely approximates the optimal C:N:P ratio for anaerobic fermentation [10], the wastewater was appropriate for biological treatment. Additionally, the $\mathrm{NaCl}$ concentration in the gallic acid wastewater was approximately $100 \mathrm{~g} / \mathrm{L}$. If fed into bioreactors directly, the processing capacity of sludge would be low under high salinity [11]. During Chinese nutgall production, a considerable amount of steam condensation water and residual circulating water are discharged, which could be used as the dilution water for the biological treatment.

An expanded granular sludge bed as an anaerobic process and bio-contact oxidation as an aerobic process were employed in this study. The expanded granular sludge bed has advantages, such as resistance to shock loading [12], less sludge formation [13], and toxicity tolerance [14], which had been applied in the treatment of various organic wastewaters containing high COD content and other complex components [15]. Bio-contact oxidation could maintain a high hydraulic load rate and retain a high biomass concentration. It could also provide resistance to high shock loading [16], promote the growth of microorganisms, and generate less sludge [17].

This study was conducted to investigate the capability of the combined process of the expanded granular sludge bed and the bio-contact oxidation reactors in the removal of COD, gallic acid, total nitrogen, and total phosphorus in Chinese nutgall processing comprehensive wastewater. In addition, changes in the $\mathrm{pH}$ of the two reactors and the redox potential in the expanded granular sludge bed were monitored during the operation.

\section{Materials and Methods}

\subsection{Reagents and Analysis}

The gallic acid standard was provided by China Pharmaceutical and Biological Products. All reagents used were of analytical reagent grade. The actual Chinese nutgall processing wastewater was obtained from HongJiang Beiya Biotech CO.,LTD. in Huaihua, Hunan province, China.

The COD level [18] and total nitrogen content [19] were assayed with a UV spectrophotometer (UV-1801; Ruili Corp, China). The total phosphorus concentration was analyzed using the molybdate spectrophotometric method [20]. The gallic acid levels were analyzed using high-performance liquid chromatography (HPLC) (Agilent 1100 series; Agilent Technologies, Germany)). The $\mathrm{pH}$ was measured by a $\mathrm{pH}$ meter using a combined electrode (pHS-3C; INESA Corporation, China). The redox potential was monitored with an acid meter with a combined redox potential electrode (320-S, Mettler Toledo, Switzerland). The inorganic elements were assayed by Inductively Coupled Plasma-Atomic Emission Spectrometry (ICP-AES) (PS-6, Baird Corp, USA).

\subsection{The Quantity and Nature of the Wastewater}

The quantity and nature of the gallic acid, 3, 4, 5-trimethoxybenzoic acid, and methyl 3, 4, 5-trimethoxy benzoate wastewater are shown in Table 1.

\subsection{Character of the Reactors and Schematic Diagram}

The industrial-scale expanded granular sludge bed reactor (200 $\mathrm{m}^{3}$ effective volume) was constructed from iron and lagging material (Fig. 2), which had a diameter of $4000 \mathrm{~mm}$, with an effective height of $18000 \mathrm{~mm}$. The bio-contact oxidation reactor $\left(900 \mathrm{~m}^{3}\right.$ effective volume) was constructed from reinforced concrete, which was composed of two independent units connected in parallel. Each independent unit in turn was composed of two independent units connected in series, each of which could be independently controlled. The bio-contact oxidation reactor measured $20000 \mathrm{~mm}$ long, $10000 \mathrm{~mm}$ wide and $5000 \mathrm{~mm}$ in height. The effective height of the bio-contact oxidation reactor was $4500 \mathrm{~mm}$; the safety height was $500 \mathrm{~mm}$; the height of the filler zone was $3000 \mathrm{~mm}$; and the aeration zone was $1000 \mathrm{~mm}$. The material of the filler was polyolefin.

The volume of the anaerobic granular sludge in the expanded granular sludge bed reactor was $60 \mathrm{~m}^{3}$, which was obtained from an anaerobic reactor in a paper mill wastewater treatment facility in Yueyang, Hunan Province, China. The volume of the aerobic sludge was $50 \mathrm{~m}^{3}$, which was acquired from an urban sewage treatment plant in Changsha, Hunan Province, China. The temperatures of the expanded granular sludge bed and the bio-contact

Table 1. Types and Characteristics of Wastewater

\begin{tabular}{lccccccc}
\hline \multicolumn{1}{c}{ Types of wastewater } & Volume $\left(\mathbf{m}^{\mathbf{3}} / \mathbf{d}\right)$ & $\mathbf{C O D}(\mathbf{m g} / \mathbf{L})$ & $\left.\mathbf{B O D}_{\mathbf{5}} \mathbf{( m g} / \mathbf{L}\right)$ & $\mathbf{T N}(\mathbf{m g} / \mathbf{L})$ & $\mathbf{T P}(\mathbf{m g} / \mathbf{L})$ & $\mathbf{p H}$ & $\mathbf{~ N a}{ }^{+}(\mathbf{m g} / \mathbf{L})$ \\
\hline gallic acid wastewater & 29.33 & 68712 & 27800 & 512.34 & 160 & 0.64 & 40171 \\
3,4,5-trimethoxybenzoic acid & 20.00 & 29186 & 13650 & 116.65 & 32.8 & 1.55 & 33824 \\
methyl 3,4,5-trimethoxybenzoate & 6.00 & 14681 & 6840 & 45.43 & 2.8 & 3.02 & 2485 \\
\hline
\end{tabular}

$\mathrm{BOD}_{5}$ : Five-day Biochemical Oxygen Demand, TN: total nitrogen, TP: total phosphorus 


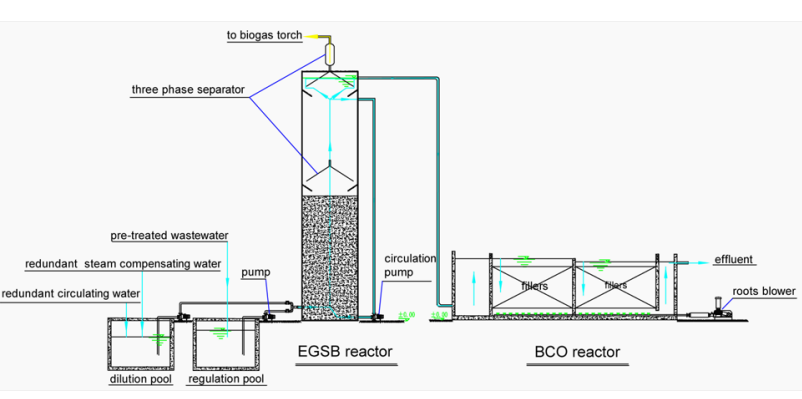

Fig. 2. Schematic diagram of the experimental setup.

oxidation reactors were maintained at $35-40^{\circ} \mathrm{C}$ and $32-37^{\circ} \mathrm{C}$ during the operation, respectively, which was conducted under mesophilic conditions.

The hydraulic retention time (HRT) was $8 \mathrm{~h}$ for the expanded granular sludge bed and $36 \mathrm{~h}$ for the bio-contact oxidation. The reactors were run under a continuous flow. The influent of the expanded granular sludge bed reactor was pre-treated comprehensive wastewater and dilution water, and the dilution water was a mixture of steam condensation water and residual circulating water. The influent of the bio-contact oxidation reactors was the effluent of the expanded granular sludge bed reactor. The rise velocity of the expanded granular sludge bed was maintained at 6-7 $\mathrm{m} / \mathrm{h}$ by adjusting the reflux ratio. The dissolved oxygen (DO) was adjusted to $2-5 \mathrm{mg} / \mathrm{L}$ for the bio-contact oxidation reactors by a Programmable Logic Controller (PLC) (PLC3U-128MR-ES-A; Mitsubishi Electric, Japan). The sludge retention time (SRT) for the expanded granular sludge bed was $10 \mathrm{~d}$, and the bio-contact oxidation was $5 \mathrm{~d}$.

\section{Results and Discussion}

\subsection{Removal of COD}

Fig. 3 shows that the COD removal efficiency by the treatment of the combined process of expanded granular sludge bed and bio-contact oxidation was high. Although the variation range of COD in the regulation pool was large, most of the time, the effluent COD of the expanded granular sludge bed was lower than $900 \mathrm{mg} / \mathrm{L}$, and lower than $400 \mathrm{~m} / \mathrm{L}$ for the bio-contact oxidation. The total removal efficiency of COD by the combined process was higher than $84.853 \%$ after $60 \mathrm{~d}$. The points on the effluent curves of the two reactors were close, indicating that the COD removal efficiency of the combined process was effective and stable.

During the run time, the average organic loading rate in the expanded granular sludge bed was $14.218 \pm 2.241 \mathrm{~kg} \mathrm{COD} /\left(\mathrm{m}^{3} \cdot \mathrm{d}\right)$ (Fig. 4), corresponding to $0.898 \pm 0.369 \mathrm{~kg} \mathrm{COD} /\left(\mathrm{m}^{3} \cdot \mathrm{d}\right)$ for bio-contact oxidation- 1 , and $0.825 \pm 0.355 \mathrm{~kg} \mathrm{COD} /\left(\mathrm{m}^{3} \cdot \mathrm{d}\right)$ for bio-contact oxidation-2. Because most refractory and toxic substances, such as gallic acid and 3, 4, 5-trimethoxybenzoic acid, that are not conducive to the biochemical treatment were separated, the remaining organic matter in the wastewater was mainly glucose. Thus, although the salinity in the regulation pool was high, the organic loading rate of the two reactor remained high.

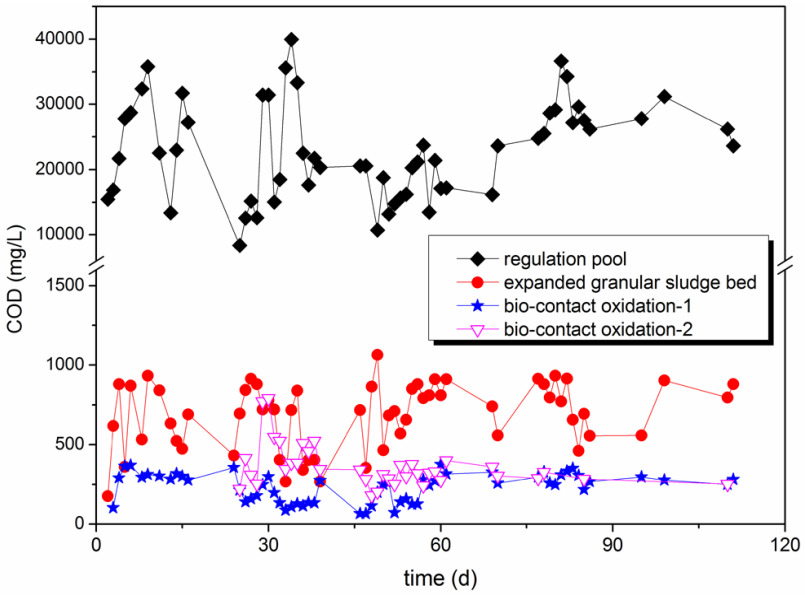

Fig. 3. The change in COD levels in the regulation pool, expanded granular sludge reactor, and bio-contact oxidation pond.

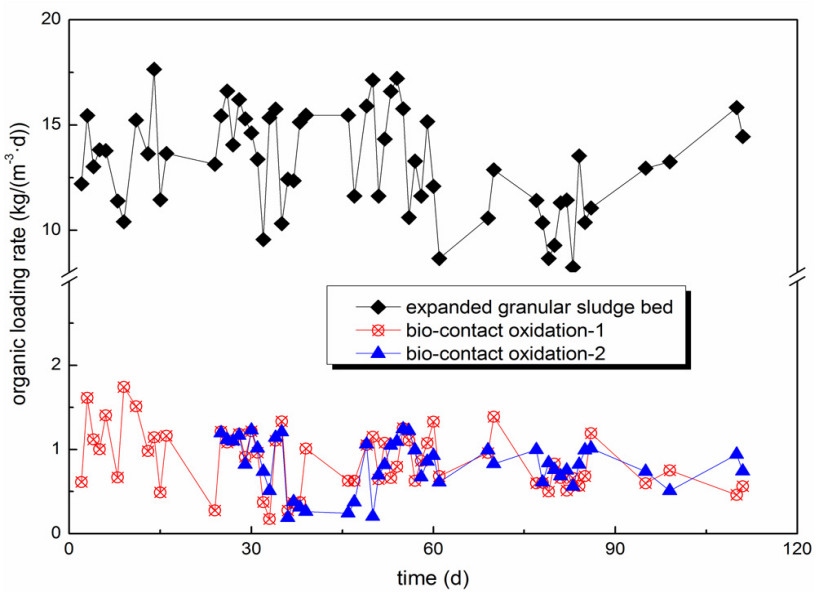

Fig. 4. Change in the organic loading rate in the expanded granular sludge bed reactor and bio-contact oxidation pond.

\subsection{Removal of Gallic Acid}

The gallic acid concentration in the regulation pool decreased with operation time. The gallic acid was removed by the flocculation pretreatment, which could adsorb part of the gallic acid and other organic matter, and also by degradation by acidifying bacteria, which increased with the operation time in the regulation pool (Fig. 5). The variation range of the gallic acid removal efficiency was large, but during most of the operation, effluent gallic acid levels were less than $50 \mathrm{mg} / \mathrm{L}$ in the expanded granular sludge bed and less than $25 \mathrm{mg} / \mathrm{L}$ for the bio-contact oxidation. The average total removal efficiency of gallic acid by the combined process was $72.221 \%$ after $60 \mathrm{~d}$.

\subsection{Removal of Chroma}

In the influent, the chroma was composed of the residual gallic acid in the gallic acid wastewater raffinate, 3, 4, 5-trimethoxybenzoic acid in the 3, 4, 5-trimethoxybenzoic acid and methyl 3, 4, 5-trimethoxybenzoate wastewater, and the pigment in the mixed comprehensive wastewater. The effect of 3, 4, 5-trimethoxybenzoic acid was ignored, as its level was very low, so the main 


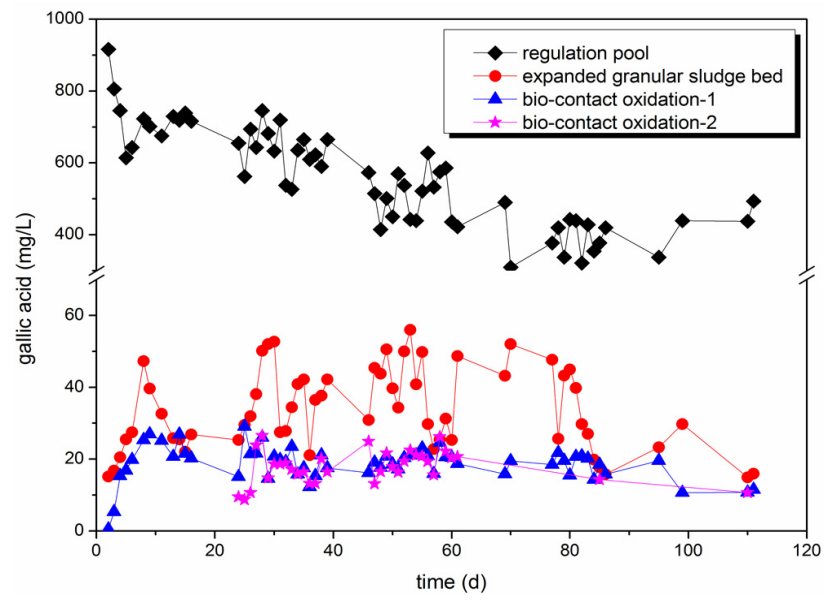

Fig. 5. Removal of gallic acid.

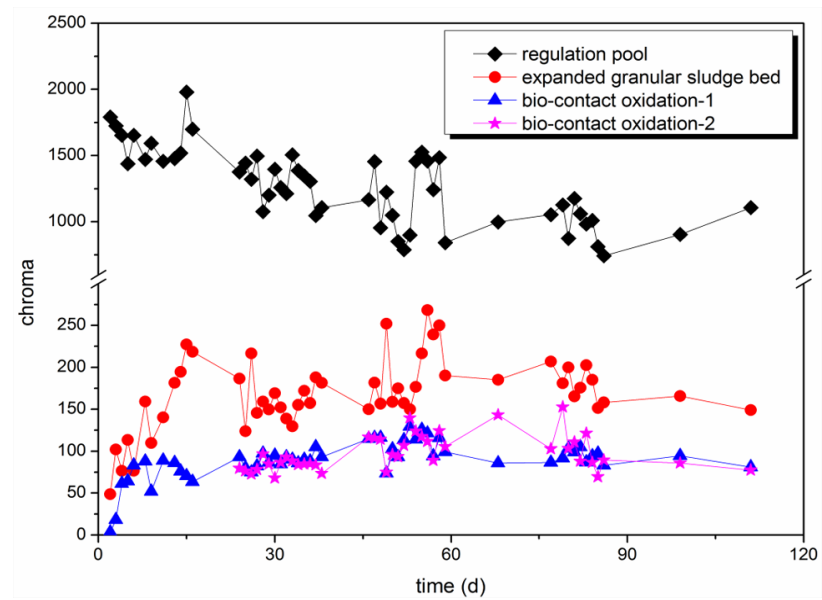

Fig. 6. Removal of chroma.

factors affecting the effluent chroma were the change in gallic acid and pigment concentrations.

Generally, the chroma is removed by biodegradation and sludge adsorption. In this study, because the sludge produced by the expanded granular sludge bed and bio-contact oxidation was minimal, the chroma was removed primarily by biodegradation. During days $1-11$, because the sludge adsorption saturated gradually, and the efficiency of the biological degradation was limited, the effluent chroma in the expanded granular sludge bed and bio-contact oxidation increased gradually (Fig. 6). When the adsorption of sludge was saturated, biodegradation was the main degradation pathway to remove the chroma. During days 11-60, because the quality of influent wastewater was unstable, the variation range of chroma was large. After 60d, the effluent chroma of the combined process was relatively stable: the average effluent chroma of the expanded granular sludge bed was $177.197 \pm 26.643,92.392 \pm 9.622$ for bio-contact oxidation- 1 , and $95.092 \pm 16.318$ for bio-contact oxidation-2. The average total removal efficiency was $43.940 \%$ after $60 \mathrm{~d}$. The effluent chroma was still too high, which required further treatment, such as flocculation, adsorption or other further treatment, to make the effluent chroma meet the discharge standard.

\subsection{Removal of Total Nitrogen}

From day 1 to 30 , the effluent total nitrogen increased gradually (Fig. 7); after $30 \mathrm{~d}$, the average effluent total nitrogen of the combined process was $31.029 \pm 6.732 \mathrm{mg} / \mathrm{L}$. The range of variation in the effluent total nitrogen of the expanded granular sludge bed reactor was $49.314-75.773 \mathrm{mg} / \mathrm{L}$, while that of the bio-contact oxidation was $20.441-39.939 \mathrm{mg} / \mathrm{L}$. The average total nitrogen removal efficiency was $64.151 \%$ after $60 \mathrm{~d}$.

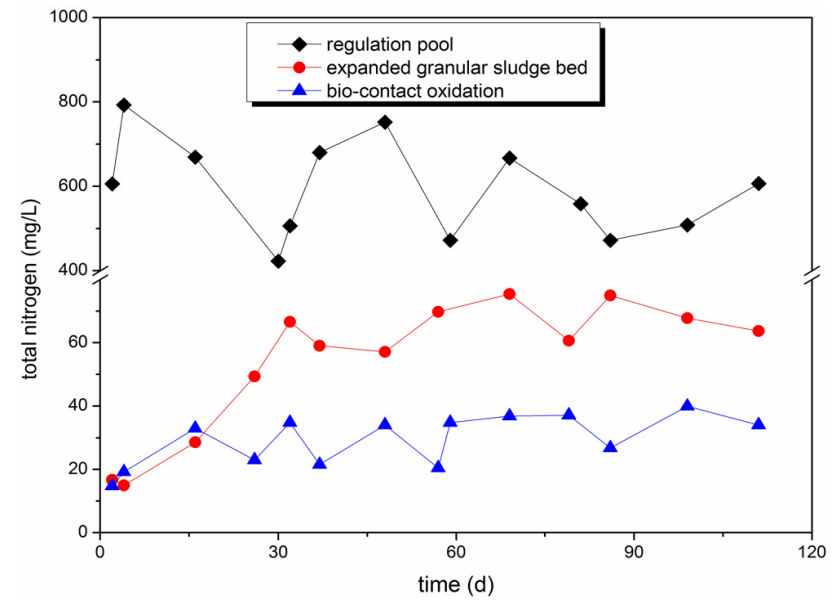

Fig. 7. Removal of total nitrogen.

\subsection{Removal of Total Phosphorus}

Similar to the removal of total nitrogen, the total phosphorus removal capability of the combined process was likewise limited. The effluent total phosphorus of both the expanded granular sludge bed and bio-contact oxidation increased gradually during the initial $49 \mathrm{~d}$ and was thereafter maintained in the range of 2.188-2.982 $\mathrm{mg} / \mathrm{L}$ (Fig. 8). The average total removal efficiency was $39.316 \%$, which demonstrated that the total phosphorus removal capacity of the combined process was poor. The SRT in this research was long, while the biological removal of phosphorus depended mainly on the discharge of adsorbed sludge. A long SRT was not conducive

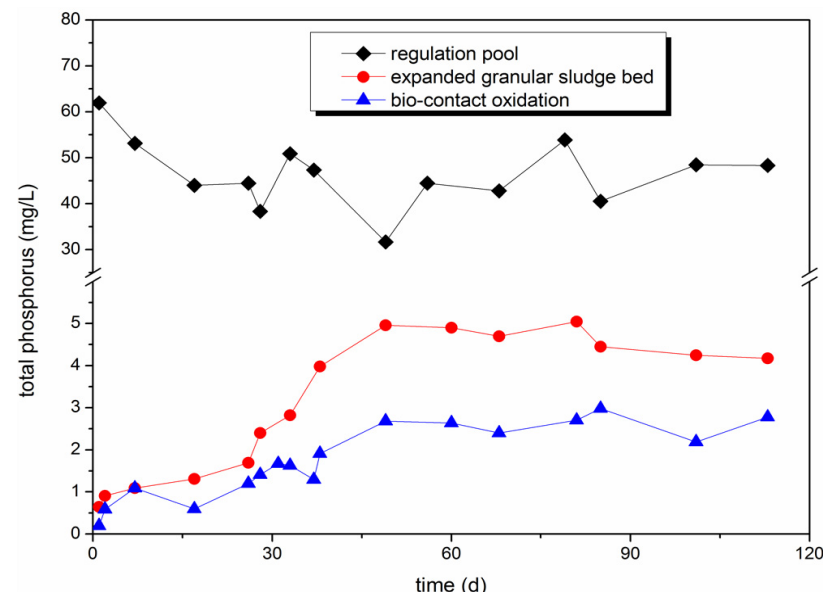

Fig. 8. Removal of total phosphorus. 
to removing the phosphorus. Therefore, the chemical phosphorus removal process needed to be combined to ensure the effluent total phosphorus complied with the emission standards.

\section{6. $\mathrm{pH}$ of Influent, Expanded Granular Sludge Bed and Bio-Contact Oxidation Reactors}

Because the $\mathrm{pH}$ regulation process was run continuously and automatically, the $\mathrm{pH}$ of the regulation pool varied in the range of 5.31-7.33, but the effluent $\mathrm{pH}$ of the expanded granular sludge bed and bio-contact oxidation was maintained at approximately 7 and 8, respectively. The curve was smooth and the change was small, thus indicating a minimal effect of the influent $\mathrm{pH}$ on the expanded granular sludge bed and bio-contact oxidation.

The effluent $\mathrm{pH}$ in the expanded granular sludge bed was 6.58-7.29, and bio-contact oxidation was 7.49-8.38, both of which were within the optimal operating range of 6-9. The anaerobic sludge granules appeared to be intact, and the removal efficiencies for COD, gallic acid, chroma, total nitrogen, and total phosphorus were stable, indicating that the expanded granular sludge bed reactor could run normally within this $\mathrm{pH}$ range. Similarly, the formed biofilm in the bio-contact oxidation reactor did not slough off, and the removal effect of the pollutants was stable, also indicating that the bio-contact oxidation could run normally and effectively (Fig. 9).

Because the majority of organic matter in the wastewater was glucose, gallic acid and 3, 4, 5-trimethoxybenzoic acid, the change in the $\mathrm{pH}$ was due to the degradation of gallic acid, glucose and 3, 4, 5-trimethoxybenzoic acid. The effluent $\mathrm{pH}$ of the expanded granular sludge bed was higher than that of the influent. In the anaerobic biochemical reaction, acid-forming bacteria degraded glucose, gallic acid and 3, 4, 5-trimethoxybenzoic acid, generating lactic acid and $\mathrm{CO}_{2}$. Methanogenic bacteria could also degrade glucose, gallic acid, 3, 4, 5-trimethoxybenzoic acid and lactic acid, thereby generating methane and $\mathrm{CO}_{2}$. The presence of lactic acid and $\mathrm{CO}_{2}$ decreased the $\mathrm{pH}$, while the reduction of gallic acid and 3, 4, 5-trimethoxybenzoic acid increased the $\mathrm{pH}$. As the $\mathrm{pH}$ in the expanded granular sludge bed was higher than that of the influent, it could be speculated that the effect of the generation

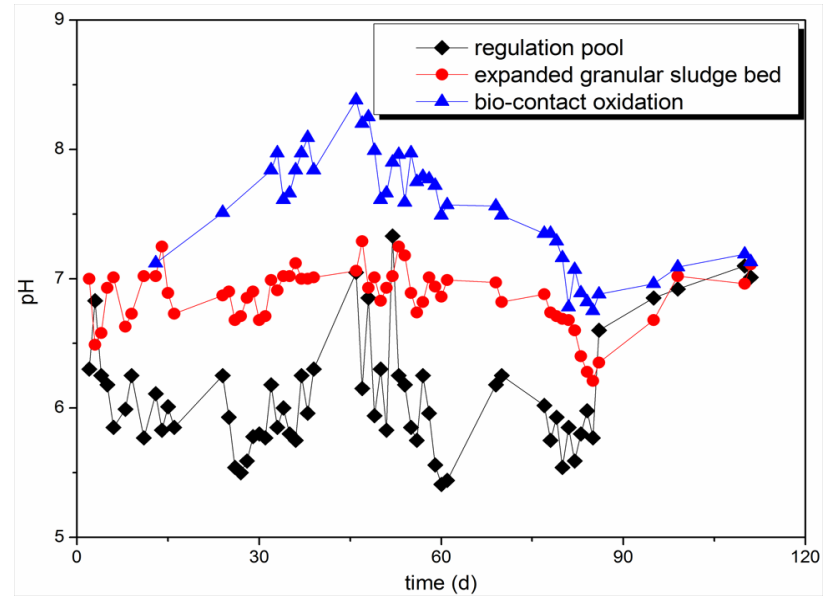

Fig. 9. $\mathrm{pH}$ of influent, expanded granular sludge bed and bio-contact oxidation reactors. of lactic acid was lower than that of gallic acid and 3, 4, 5-trimethoxybenzoic acid degradation. It also indirectly demonstrated that the activity of the acid-forming bacteria was weaker than that of the methanogenic bacteria. In addition, the $\mathrm{pH}$ in the effluent of the bio-contact oxidation reactor was higher than in the influent because of the degradation of gallic acid and the blow off of $\mathrm{CO}_{2}$.

\subsection{Changes in the Redox Potential in the Expanded Granular Sludge Bed Reactor}

During the initial $12 \mathrm{~d}$, the redox potential in the expanded granular sludge bed decreased from $-270 \mathrm{mV}$ to $-367 \mathrm{mV}$ (Fig. 10), thereafter fluctuating between $-367 \mathrm{mV}$ and $-435 \mathrm{mV}$, thus indicating that the microenvironment in the expanded granular sludge bed was stable and suitable for the metabolism of the methanogenic bacteria [21].

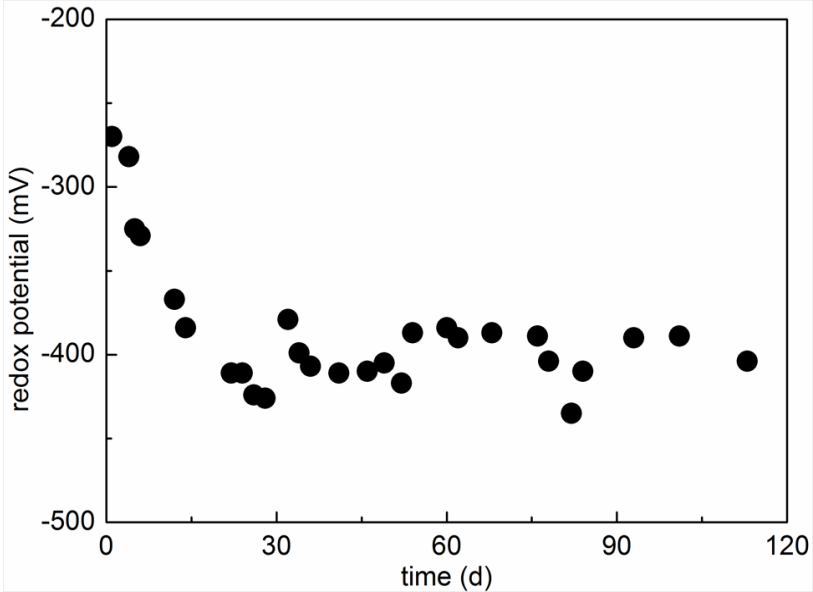

Fig. 10. Changes in the redox potential in the expanded granular sludge bed reactor.

\section{Conclusions}

In this study, we investigated the treatment of Chinese nutgall processing wastewater with an industrial-scale expanded granular sludge bed reactor inoculated with anaerobic granular sludge and a bio-contact oxidation reactor inoculated with polyolefin and aerobic flocculent sludge. The results indicated that the combined process of the expanded granular sludge bed and bio-contact oxidation reactors were feasible for the biological treatment of Chinese nutgall processing wastewater under mesophilic conditions $\left(30-40^{\circ} \mathrm{C}\right)$, which is currently not a common practice. An average COD removal efficiency of $87.257 \%$ was achieved when the influent COD concentration was $14251 \pm 3148 \mathrm{mg} / \mathrm{L}$, and the ratio of the wastewater and dilution water was 1:5. The removal efficiencies of gallic acid, chroma, total nitrogen, and total phosphorus were $72.221 \%$, $43.940 \%, 64.151 \%$ and $39.316 \%$, respectively. The effluent $\mathrm{pH}$ increased both in the expanded granular sludge bed and in the bio-contact oxidation reactor during the operation. The redox potential in the expanded granular sludge bed reactor varied in the range of $-367 \mathrm{mV}$ to $-435 \mathrm{mV}$. To comply with the emission standards, the effluent required additional treatment. 


\section{References}

1. Okabe N, Kyoyama H, Suzuki M. Gallic acid monohydrate. Acta Crystallogr. Sect. E Struct. Rep. Online 2001;57:764-766.

2. Herath K B, Weisbecker C S, Singh S B, et al. Circumambulatory Movement of Negative Charge ("Ring Walk") during Gas-Phase Dissociation of 2, 3, 4-Trimethoxybenzoate Anion. J. Org. Chem. 2014;79:4378-4389.

3. Qin Q. Techniques for treatment and recovery of effluents, residues and wasted carbon from gallic acid production. J. Chem. Ind. Forest Products 2000;34:15-20.

4. Wu Y D, Zhou K G ,Dong S Y, et al. Recovery of gallic acid from gallic acid processing wastewater. Environ. Technol. 2015;36:661-666.

5. Chen Y, Cheng J J, Creamer K S. Inhibition of anaerobic digestion process: a review. Bioresour. Technol. 2008;99:4044-4064.

6. Beltrán F J, Encinar J M, García-Araya J F. Oxidation by ozone and chlorine dioxide of two distillery wastewater contaminants: gallic acid and epicatechin. Water Res. 1993;27:1023-1032.

7. Panizza M, Cerisola G. Electrochemical degradation of gallic acid on a BDD anode. Chemosphere 2009;77:1060-1064.

8. Kozlovskaya V, Kharlampieva E, Drachuk I, et al. Responsive microcapsule reactors based on hydrogen-bonded tannic acid layer-by-layer assemblies. Soft Matter 2010;6:3596-3608.

9. Uhde A, Youn J, Maeda T, et al. Glucosamine as carbon source for amino acid-producing Corynebacterium glutamicum. Appl. Microbiol. Biotechnol. 2013;97:1679-1687.

10. Baron J A, Laws K M, Chen J S, et al. Superoxide triggers an acid burst in Saccharomyces cerevisiae to condition the environment of glucose-starved cells. J. Biol. Chem. 2013;288: 4557-4566.

11. Zheng M X, Wang K J, Zuo J E, et al. Flow pattern analysis of a full-scale expanded granular sludge bed-type reactor under different organic loading rates. Bioresour. Technol. 2012;107:
33-40.

12. Pronk M, Bassin J, de Kreuk M, et al. Evaluating the main and side effects of high salinity on aerobic granular sludge. Appl. Microbiol. Biotechnol. 2014;98:1339-1348.

13. Costa J C, Abreu A A, Ferreira E C, et al. Quantitative image analysis as a diagnostic tool for monitoring structural changes of anaerobic granular sludge during detergent shock loads. Biotechnol. Bioeng. 2007;98:60-68.

14. Abbasi T, Abbasi S A. Formation and impact of granules in fostering clean energy production and wastewater treatment in upflow anaerobic sludge blanket (UASB) reactors. Renew.Sust. Energ. Rev. 2012;16:1696-1708.

15. Pereira M A, Mota M, Alves M M. Operation of an anaerobic filter and an EGSB reactor for the treatment of an oleic acid-based effluent: influence of inoculum quality. Process Biochem. 2002;37:1025-1031.

16. Lopez J, Monsalvo V M, Puyol D, et al. Low-temperature anaerobic treatment of low-strength pentachlorophenol-bearing wastewater. Bioresour. Technol. 2013;140:349-356.

17. Wang J, Chen J. Removal of dichloromethane from waste gases with a bio-contact oxidation reactor. Chem. Eng. J. 2006;123: 103-107.

18. Pliego G, Zazo J A, Casas J A, et al. Case study of the application of Fenton process to highly polluted wastewater from power plant. J. Hazard. Mater. 2013;252:180-185.

19. Roig B,Gonzalez C, Thomas O. Measurement of dissolved total nitrogen in wastewater by UV photooxidation with peroxodisulphate. Anal. Chim. Acta 1999;389:267-274.

20. Hongyan T, Guodong Z. Evaluation of Uncertainty for the Determination of Total Phosphorus in the Wastewater by Ammonium Molybdate Spectrophotometric Method. Environ. Sci. Manage. 2011;36:143-146.

21. Weiland P. Biogas production: current state and perspectives. Appl. Microbiol. Biotechnol. 2010;85:849-860. 